\title{
Desenvolvimento e caracterização de filmes à base de Poli(3-hidroxibutirato) aditivado com ZnOnano
}

\author{
Development and characterization of films based on \\ Poly(3- hydroxybutyrate) with added ZnOnano
}

\author{
Reginaldo Gomes de Lima Júnior ${ }^{1}$, Glória Maria Vinhas ${ }^{2 \star}$, Rosa Maria Souto-Maior ${ }^{3}$, \\ Andrelina Maria Pinheiro Santos ${ }^{4}$, Edval José Pinheiro Santos ${ }^{4}$, Yêda Medeiros Bastos de Almeida ${ }^{2}$ \\ ${ }_{1}^{1}$ Universidade Federal de Pernambuco (UFPE), Centro de Ciências Exatas e da Natureza, Pós-graduação em Ciência de Materiais, Recife/PE - Brasil \\ 2 Universidade Federal de Pernambuco (UFPE), Departamento de Engenharia Química, Laboratório de Materiais Poliméricos e Caracterização (LMPC), \\ Recife/PE - Brasil \\ ${ }^{3}$ Universidade Federal de Pernambuco (UFPE), Departamento de Química Fundamental, Recife/PE - Brasil \\ ${ }^{4}$ Universidade Federal de Pernambuco (UFPE), Centro de Tecnologia e Geociências (CTG), Laboratório de Dispositivos e Nanoestrutura (LDN), \\ Recife/PE - Brasil
}

\section{${ }^{*}$ Corresponding Author}

Glória Maria Vinhas, Universidade Federal de Pernambuco (UFPE), Departamento de Engenharia Química, Laboratório de Materiais Poliméricos e Caracterização (LMPC), Avenida Prof. Moraes Rego, 1235, Cidade Universitária, CEP: 50670-901, Recife/PE - Brasil, e-mail: gmvinhas@yahoo.com.br

Cite as: Development and characterization of films based on Poly(3- hydroxybutyrate) with added ZnOnano. Braz. J. Food Technol., v. 19, e2015082, 2016.

Received: Oct. 21, 2015; Accepted: June 21, 2016

\section{Resumo}

Filmes de Poli(3-hidroxibutirato) (PHB) foram produzidos com a adição de óxido de zinco nanoestruturado (ZnOnano) em diferentes proporções $(1 \%, 3 \%, 5 \% \mathrm{~m} / \mathrm{m})$. Os filmes foram caracterizados por TGA, DSC, MEV e infravermelho. A atividade antimicrobiana dos filmes na presença da bactéria E. coli também foi avaliada. Foram obtidos filmes homogêneos com boa dispersão das nanopartículas na matriz polimérica. A estabilidade do polímero não foi comprometida pelas nanopartículas, que funcionaram como agentes nucleantes aumentando a cristalinidade do polímero. A análise por componentes principais (PCA) mostrou que a nanocarga alterou as vibrações dos grupos funcionais indicando a existência de interações entre o ZnO e o polímero. O filme nanocompósito contendo $5 \%$ do óxido inibiu o crescimento da bactéria patogênica $E$. coli, mostrando-se, portanto, promissor em aplicações na indústria de embalagens para alimentos.

Palavras-chave: Atividade antimicrobiana; PHB; Nanopartículas de ZnO; Análise por componentes principais; Análise térmica.

\section{Summary}

Industrial Poly(hydroxybutyrate) PHB films were produced with the addition of nanostructured zinc oxide (ZnOnano) in different proportions (1,3,5\% w/w). The films were characterized by thermogravimetric analysis (TGA), differential scanning calorimetry (DSC), scanning electron microscopy (SEM) and infrared spectroscopy (FTIR). The antimicrobial activity against the bacteria E. coli was also evaluated. Homogeneous films with good dispersion of the nanoparticles in the polymer matrix were obtained. The stability of the polymer was not compromised by the nanoparticles, which functioned as nucleating agents to increase the crystallinity of the polymer. The principal component analysis (PCA) showed that the nanoclay modified the vibrations of the functional groups, indicating the existence of interactions between the polymer and $\mathrm{ZnOnano}$. The nanocomposite film containing $5 \%$ of ZnOnano inhibited the growth of pathogenic E. coli., thus showing promise for applications in the food packaging industry.

Keywords: Antimicrobial activity; PHB; ZnO nanoparticles; Principal component analysis; Thermal analysis. 


\section{Introdução}

O desenvolvimento de novos materiais para obtenção de embalagens ativas visa atender à nova exigência do mercado para embalagens de alimentos, considerado um conceito inovador com uma tecnologia emergente, em que um aditivo é incorporado ao material de embalagem com a finalidade de interagir com o alimento, atuando na liberação ou absorção de substâncias, podendo fornecer e/ou melhorar a funcionalidade, pois passa a conferir diferentes propriedades além da função de proteção, atuando na extensão da vida comercial do produto embalado (GÓMEZ-ESTACA et al., 2014; LÓPEZ DE DICASTILLO et al., 2011). Neste contexto, diferentes aditivos que podem atuar como agentes antioxidantes e/ou antimicrobianos conferem ao alimento embalado maior proteção contra fatores internos e externos, reduzindo a adição de conservantes no processamento desses alimentos. Dentre esses aditivos, nanopartículas de ZnO podem apresentar potencial aplicação para obtenção de embalagens ativas devido à sua ação antimicrobiana. Estudos mostram que a adição de $\mathrm{ZnO}$ em meios de cultura proporciona significativa inibição do crescimento de L. monocytogenes, S. enteritidis e E. coli (ESPITIA et al., 2012; JIN et al., 2009) e um bom efeito bacteriostático para o $S$. agalactiae e $S$. aureus, que são dois agentes etiológicos de várias doenças infecciosas em seres humanos (HUANG et al., 2008).

Outro aspecto importante no desenvolvimento de filmes para embalagens ativas é a escolha do material polimérico que reduza o impacto ambiental. O Poli(3-hidroxibutirato) (PHB), um polímero biodegradável e biocompatível, termoplástico, semicristalino e linear, produzido a partir de recursos renováveis (WELLEN et al., 2013), apresenta propriedades similares aos polímeros petroquímicos usados para as embalagens de alimentos (BRUZAUD; BOURMAUD, 2007). Pesquisas são realizadas com PHB para diminuir sua cristalinidade e aumentar a estabilidade térmica no processamento, melhorar as propriedades mecânicas, de barreira e antimicrobiana, de forma a ampliar as possibilidades de suas aplicaçãões (BRUZAUD; BOURMAUD, 2007; D'AMICO et al., 2012; SILVA et al., 2013; DÍEZ-PASCUAL; DÍEZ-VICENTE, 2014). Uma dessas propriedades, a cristalinidade, está relacionada ao processamento do polímero e é determinante para a obtenção de filmes com propriedades mecânicas adequadas à sua aplicação como embalagem (ARIFFIN et al., 2008; BOTANA et al., 2010; ABDELWAHAB et al., 2012).

Portanto, este trabalho teve como proposta desenvolver filmes de PHB incorporados com nanopartículas de ZnO (ZnOnano), avaliar sua ação antimicrobiana na presença da bactéria E. coli, morfologia (MEV), cristalinidade (DSC), estabilidade térmica (TGA) e estrutura química do filme (FTIR e PCA).

\subsection{Materiais}

Foi utilizado poli(hidroxibutirato) (PHB) da PHB Industrial Ltda. (São Paulo, Brasil), na forma de pó, sem purificação, e clorofórmio Vetec (99\%) para a preparação dos filmes. O ZnOnano com tamanho de partícula $<150 \mathrm{~nm}$ foi produzido pelo grupo do Laboratório de Dispositivos e Nanoestrutura (LDN/Universidade Federal de Pernambuco), sendo sintetizado a baixas temperaturas $\left(50\right.$ a $\left.70^{\circ} \mathrm{C}\right)$, sob constante agitação (800 rpm), conforme metodologia de Santos e Santos (2008).

\subsection{Métodos}

\subsubsection{Preparação dos filmes de PHB/ZnOnano}

A preparação dos filmes foi realizada de acordo com as condições apresentadas na Tabela 1. O PHB (1,3 g) em pó foi solubilizado em $40 \mathrm{~mL}$ de clorofórmio sob agitação a $60^{\circ} \mathrm{C}$. Depois da completa dissolução do $\mathrm{PHB}$, foi adicionado o ZnOnano, mantendo a mistura sob agitação na mesma temperatura até observar a dispersão completa do ZnOnano no gel de PHB. Em seguida, a mistura de $\mathrm{PHB} / \mathrm{nanoZnO}$ foi transferida para placas de petri $(100 \times 20 \mathrm{~mm})$ e secados em estufa $(40 \mathrm{~L})$, por $24 \mathrm{~h}$ a $25 \pm 2{ }^{\circ} \mathrm{C}$. No final, foram obtidos filmes com uma espessura média de $250 \pm 40 \mu \mathrm{m}$. Estes filmes foram utilizados nas análises de caracterização.

\subsubsection{Atividade antimicrobiana: teste do halo}

Discos dos filmes de PHB puro e dos filmes $\mathrm{PHB} / \mathrm{ZnOnano}$ de aproximadamente $10 \mathrm{~mm}$ de diâmetro foram acondicionados entre lâminas e inseridos em placas de petri para serem esterilizados em autoclave a $121^{\circ} \mathrm{C}$ por 15 minutos. Depois da esterilização, os filmes foram inseridos assepticamente em placas de petri contendo o meio Agar Nutritivo, previamente inoculadas com $0,1 \mathrm{~mL}$ de suspensão de Escherichia coli $\left(10^{-4}\right.$ na escala MacFarland). A incubação foi a $30^{\circ} \mathrm{C}$ por 24 horas. Depois do crescimento microbiano, foi feita a medida do halo de inibição dos filmes.

\subsection{Caracterização dos filmes}

Os filmes que apresentaram melhor homogeneidade nas concentrações de 1\%, 3\% e 5\% de nano $\mathrm{ZnO}$, elaborados de acordo com as condições apresentadas na Tabela 1, foram selecionados para caracterização por FTIR, DSC, TGA, MEV e atividade antimicrobiana.

\subsubsection{Espectroscopia no infravermelho (FTIR)}

As análises de espectroscopia no infravermelho (FTIR) dos filmes de PHB puro e PHB/ZnOnano (1\%, 3\% e 5\%) foram realizadas no Espectrômetro Bruker - Tensor 27 , software Opus. As amostras foram prensadas em pastilhas 
Tabela 1. Matriz do planejamento de experimentos utilizada na elaboração dos filmes de PHB/ZnOnano.

\begin{tabular}{ccccc} 
Ensaio & $\begin{array}{c}\text { Zno } \\
(\%)\end{array}$ & $\begin{array}{c}\text { Temperatura } \\
\left({ }^{\circ} \mathbf{C}\right)\end{array}$ & $\begin{array}{c}\text { Agitação } \\
(\mathbf{r p m})\end{array}$ & $\begin{array}{c}\text { Tempo de } \\
\text { mistura } \\
\mathbf{( m i n})\end{array}$ \\
\hline controle & - & $\mathbf{6 0}$ & $\mathbf{1 0 0 0}$ & $\mathbf{1 8 0}$ \\
\hline 01 & $(-1) 1$ & $(-1) 50$ & $(-1) 750$ & $(-1) 120$ \\
02 & $(+1) 5$ & $(-1) 50$ & $(-1) 750$ & $(+1) 240$ \\
03 & $(-1) 1$ & $(+1) 70$ & $(-1) 750$ & $(+1) 240$ \\
04 & $(+1) 5$ & $(+1) 70$ & $(-1) 750$ & $(-1) 120$ \\
05 & $(-1) 1$ & $(-1) 50$ & $(+1) 1250$ & $(+1) 240$ \\
06 & $(+1) 5$ & $(-1) 50$ & $(+1) 1250$ & $(-1) 120$ \\
07 & $(-1) 1$ & $(+1) 70$ & $(+1) 1250$ & $(-1) 120$ \\
08 & $(+1) 5$ & $(+1) 70$ & $(+1) 1250$ & $(+1) 240$ \\
09 & $(0) 3$ & $(0) 60$ & $(0) 1000$ & $(0) 180$ \\
10 & $(0) 3$ & $(0) 60$ & $(0) 1000$ & $(0) 180$ \\
11 & $(0) 3$ & $(0) 60$ & $(0) 1000$ & $(0) 180$ \\
\hline
\end{tabular}

de $\mathrm{KBr}$ e os espectros obtidos com resolução de $4 \mathrm{~cm}^{-1} \mathrm{e}$ 16 scans, utilizando a faixa espectral de 4000 a $400 \mathrm{~cm}^{-1}$.

\subsubsection{Análise por componentes principais (PCA)}

A PCA é uma técnica quimiométrica de reconhecimento de padrões, ou seja, utiliza ferramentas matemáticas e estatísticas para explorar os resultados obtidos em análises químicas. Através da redução de dimensões, permite detectar padrões ou agrupamento de amostras com características semelhantes, estabelecer quais variáveis são correlacionadas ou redundantes e observar amostras anômalas. A redução da dimensão do espaço de parâmetros é realizada através da transformação da variável original, representando-a em novos eixos (SANTOS; SANTOS, 2008). Para análise da PCA, foi utilizado o software Unscrambler, versão 9.7. Foi construída uma matriz de dados multivariados, na qual cada variável representa um eixo do espaço matemático das características das amostras. Manipulações algébricas na matriz de covariância das variáveis e novos eixos foram calculados, no sentido da maior variância. Esses novos eixos são as componentes principais (PCs). A matriz de dados analisada foi de espectros, sem pré-processamento, das amostras de PHB puro e PHB/ZnOnano (1\%, 3\% e 5\%).

\subsubsection{Calorimetria Exploratória Diferencial (DSC)}

Os filmes foram caracterizados por calorimetria exploratória diferencial (DSC- METTLER TOLEDO DSC1 STARe system), utilizando cadinho de alumínio ( $40 \mu \mathrm{L}$, com tampa) sob atmosfera de nitrogênio com fluxo de $50 \mathrm{~mL} / \mathrm{min}$. Os testes foram realizados com amostras de 3 a $6 \mathrm{mg}$, em três estágios: aquecimento de $-20^{\circ} \mathrm{C}$ a $200^{\circ} \mathrm{C}$, com taxa de aquecimento de $10^{\circ} \mathrm{C} / \mathrm{min}$, resfriamento até $25^{\circ} \mathrm{C}$, com taxa de resfriamento de $5^{\circ} \mathrm{C} / \mathrm{min}$, e reaquecimento até $200^{\circ} \mathrm{C}$, com taxa de $10^{\circ} \mathrm{C} / \mathrm{min}$.
A temperatura e entalpia de fusão foram calculadas a partir da área do pico máximo endotérmico. A cristalinidade relativa $\left(X_{C}\right)$ e a taxa de cristalização $(c)$ foram calculadas utilizando o software INTEGRAL ${ }^{\mathrm{TM}}$, desenvolvido na Universidade Federal de Campina Grande, utilizando a entalpia para o PHB 100\% cristalino correspondente a $146 \mathrm{~J} / \mathrm{g}$ (ABDELWAHAB et al., 2012).

\subsubsection{Análise termogravimétrica (TGA)}

Para avaliação da estabilidade térmica dos compósitos e dos seus constituintes, foram realizadas análises termogravimétricas no equipamento Perkin Elmer STA 6000, software Pyres, com uma razão de aquecimento de $20^{\circ} \mathrm{C} / \mathrm{min}$, sob atmosfera de nitrogênio com vazão do gás de $50 \mathrm{~mL} / \mathrm{min}$. Foi utilizado cadinho de platina e $15 \mathrm{mg}$ de material para cada análise. As faixas de temperatura desta análise foram de $25^{\circ} \mathrm{C}$ a $450{ }^{\circ} \mathrm{C}$.

\subsubsection{Caracterização morfológica}

A análise por microscopia eletrônica de varredura (MEV) foi realizada utilizando um microscópio JEOL 6460. Os filmes de PHB/ZnOnano foram fixados ao stub com fita de carbono, montados no suporte e revestidos com uma fina camada de ouro, com uma tensão de $20 \mathrm{kV}$.

\section{Resultados e discussões}

\subsection{Filme PHB/ZnOnano}

A Figura 1 apresenta as imagens dos filmes de PHB e dos nanocompósitos. Cada filme apresenta uma característica diferenciada quanto à homogeneidade, mostrando o efeito da combinação dos parâmetros temperatura, agitação e tempo na produção do filme. De uma forma geral, os filmes que apresentaram maior uniformidade foram os dos ensaios 03, 04, 08 e 11.

\subsection{Atividade antimicrobiana}

A Figura 2 mostra o filme (Ensaio 04) na forma de disco na superfície da placa de petri incubada com a linhagens de E. coli. A Figura 2A apresenta o filme de PHB puro que não mostra nenhuma inibição, na qual pode-se perceber o crescimento da bactéria ao redor do filme. Na Figura 2B, o filme de PHB/ZnOnano (5\%) apresenta uma perceptível região ao redor do filme na qual não houve crescimento da bactéria, caracterizando sua inibição em contato com as nanoestruturas. $O$ efeito da ação dos nanocompósitos foi avaliada por Hajipour e colaboradores (HAJIPOUR et al., 2012), que relataram que a tolerância de micro-organismos está diretamente relacionada com o tamanho dos óxidos e as interações dessas nanoestruturas, na membrana do patógeno. Em relação ao mecanismo de ação das nanopartículas de $\mathrm{ZnO}$, objetivo deste estudo, apesar de existirem 
Desenvolvimento e caracterização de filmes à base de Poli(3-hidroxibutirato) aditivado com ZnOnano Lima Júnior, R. G. et al.

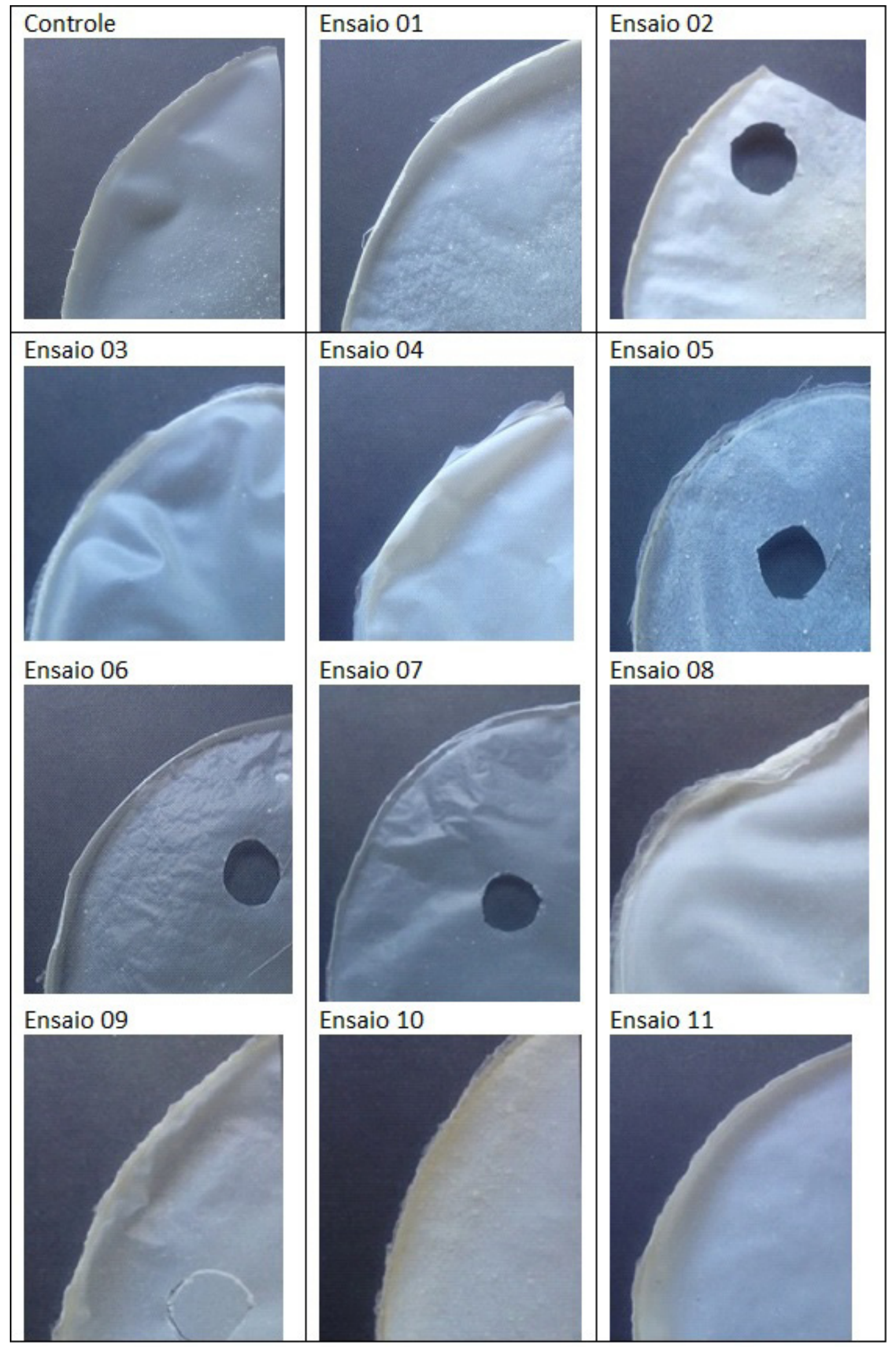

Figura 1. Filmes PHB/ZnOnano em diferentes condições de processamento. 
Desenvolvimento e caracterização de filmes à base de Poli(3-hidroxibutirato) aditivado com ZnOnano

Lima Júnior, R. G. et al.
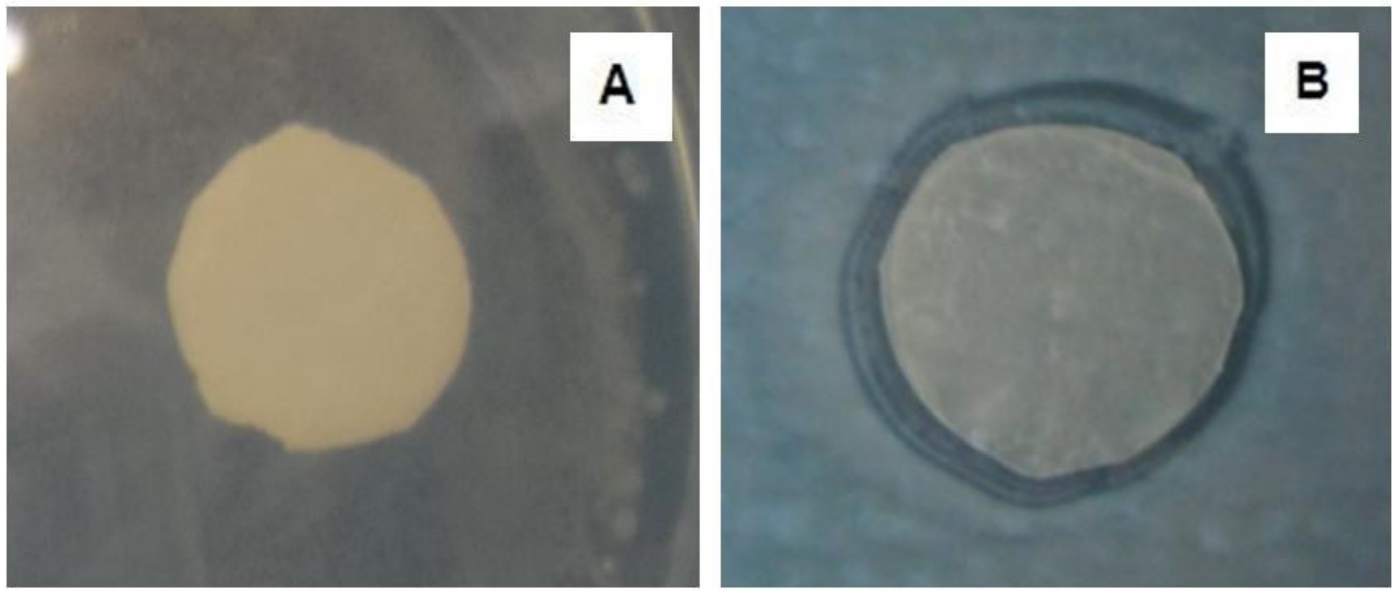

Figura 2. Amostra de PHB puro (A) e halo formado devido à ação antimicrobiana na amostra de PHB/ZnOnano (5\%) (B).

trabalhos sobre a toxicidade em células bacterianas (PADMAVATHY; VIJAYARAGHAVAN, 2008; LIPOVSKY et al., 2011; DÍEZ-PASCUAL; DÍEZ-VICENTE, 2014), ainda não existe um consenso. De acordo com Hajipour et al. (2012), os principais mecanismos de toxicidade encontrados na literatura são: interação eletrostática, formação de estresse oxidativo, geração de espécies de oxigênio reativo, ruptura da membrana, aumento da permeabilidade na membrana. Os filmes de PHB/ZnOnano (1\% e 3\%) não apresentaram atividade microbiana provavelmente pelo baixo percentual de $\mathrm{ZnO}$.

\subsection{Análise de infravermelho}

As Figuras 3 e 4 mostram o espectro de infravermelho dos filmes de PHB puro e dos filmes de PHB/ZnOnano (1\%, 3\% e $5 \%$ ) na região de 1800 a $1000 \mathrm{~cm}^{-1}$ e de 4000 a $2700 \mathrm{~cm}^{-1}$, respectivamente. As bandas vibracionais mais importantes estão apresentadas na Tabela 2 e os resultados obtidos são coerentes com os encontrados na literatura (ROA et al., 2013).

Devido à sua complexidade, os espectros de infravermelho foram investigados por análise de componentes principais (PCA), uma ferramenta quimiométrica que avalia o espectro incluindo todas as bandas vibracionais. O gráfico de escores da PC1 × PC2 (Figura 5) evidenciou a formação de dois agrupamentos distintos, em função de suas estruturas químicas: um agrupamento são os filmes de $\mathrm{PHB} / \mathrm{ZnO}$ nas três composições (em azul) e o outro refere-se ao filme de $\mathrm{PHB}$ puro (em vermelho). Este resultado sugere a existência de interações intermoleculares entre o ZnO e o polímero, que se refletem nas bandas vibracionais características do PHB.

\subsection{Morfologia do filme}

A microscopia eletrônica de varredura foi utilizada para investigar a dispersão de ZnOnano na matriz de polímero e uma micrografia representativa é apresentada na Figura 6. A Figura 6A indica uma superfície homogênea

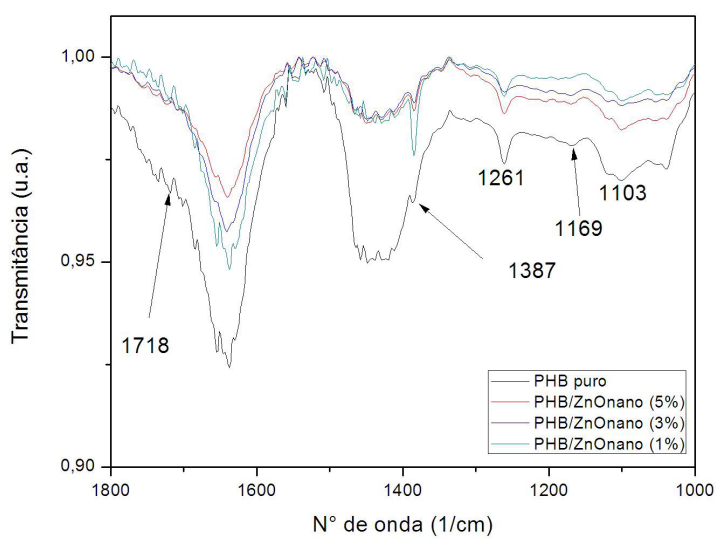

Figura 3. Espectros de infravermelho dos filmes de PHB puro e $\mathrm{PHB} / Z n O n a n o ~(1 \%, 3 \%$ e 5\%), ampliação do espectro entre 1800 e $1000 \mathrm{~cm}^{-1}$.

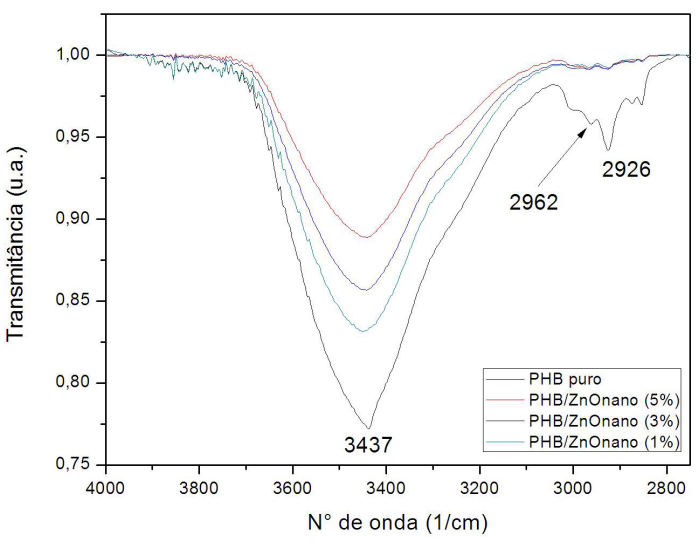

Figura 4. Espectros de infravermelho dos filmes de PHB puro e PHB/ZnOnano (1\%, 3\% e 5\%), ampliação do espectro entre 4000 e $2700 \mathrm{~cm}^{-1}$. 


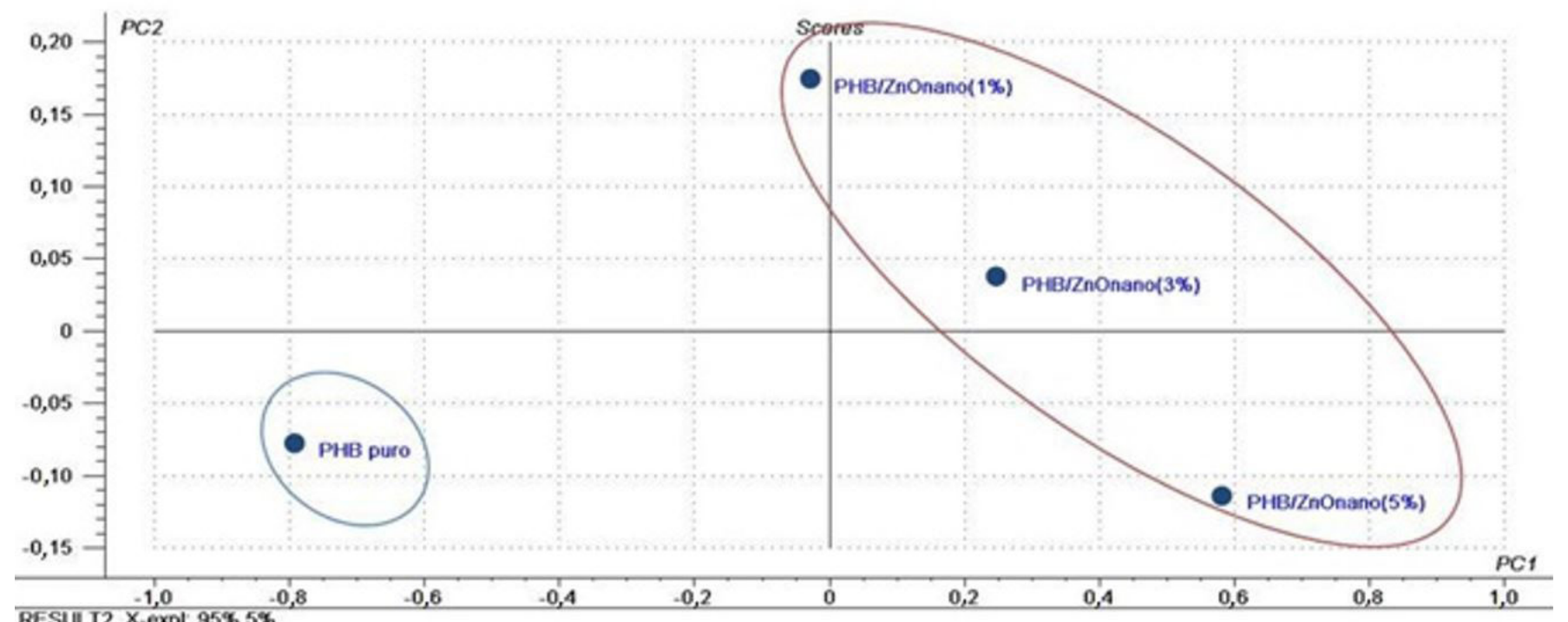

Figura 5. Gráfico de escores PC1 e PC2.
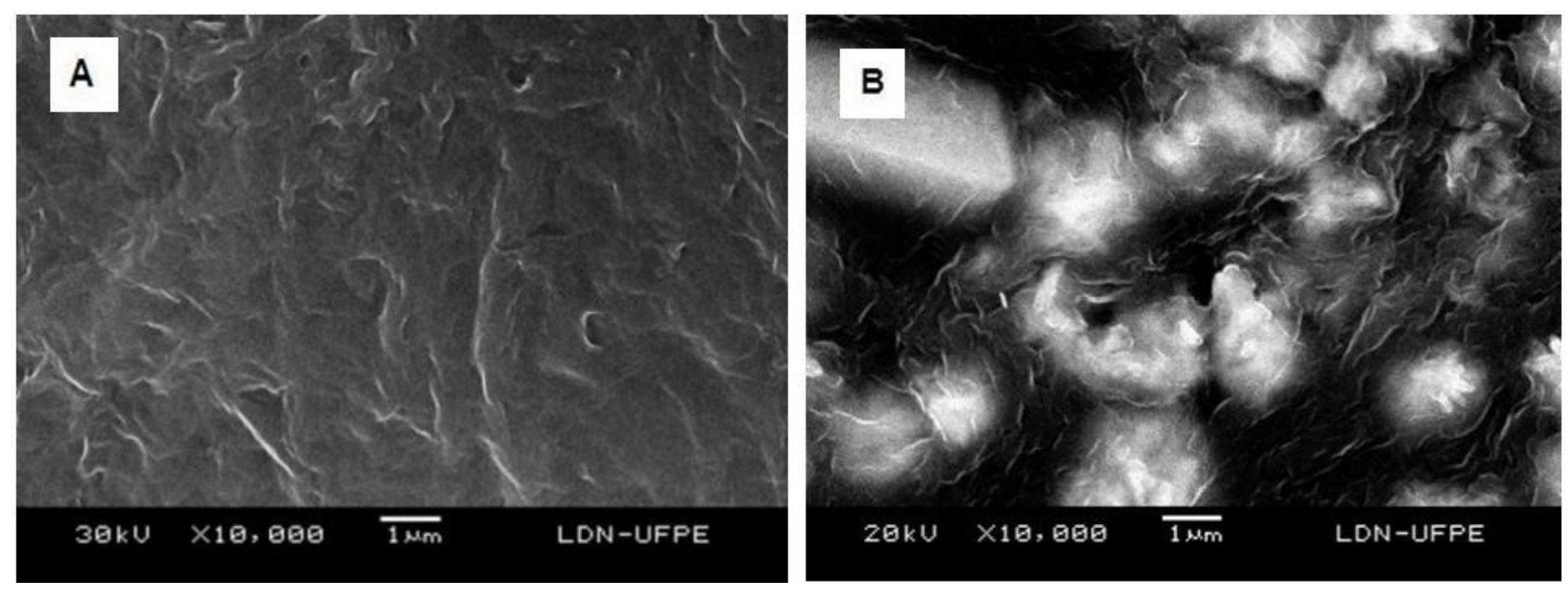

Figura 6. Micrografia de superfície dos filmes para: (A) PHB/ZnOnano 5\% ampliação $1 \mathrm{~K}$ e (B) PHB/ZnOnano 5\% ampliação de $10 \mathrm{~K}$.

Tabela 2. Atribuição das bandas vibracionais no infravermelho médio das amostras de PHB puro e PHB/ZnOnano (1\%, 3\% e $5 \%$ ). As bandas em $3437 \mathrm{~cm}^{-1}$ e $1637 \mathrm{~cm}^{-1}$ devem-se à água presente nas amostras.

\begin{tabular}{cc} 
Tipo de vibração & $\begin{array}{c}\text { Número de onda } \\
\left(\mathbf{c m}^{-1} \mathbf{)}\right.\end{array}$ \\
\hline Estiramento $\mathrm{C}=\mathrm{O}$ & 1718 \\
Estiramento $-\mathrm{CH}_{3}$ & 2962 \\
Estiramento $-\mathrm{CH}_{2}-$ & 2926 \\
Estiramento $\mathrm{C}-\mathrm{O}$ & 1261,1169 \\
Estiramento $\mathrm{CH}_{3}-$ angular & 1387 \\
\hline
\end{tabular}

e sem poros, o que sugere uma boa formação do filme de $\mathrm{PHB} / Z n O n a n o$ (5\%). O ZnOnano foi incorporado na matriz de PHB com uma boa dispersão, como pode ser visto na Figura 6B. Uma observação feita por Raghupathi et al.
(2011) afirma que uma boa dispersão das nanopartículas na matriz polimérica garante uma boa eficácia na inibição microbiana, e que essa eficiência diminui com a aglutinação das nanocargas. Isto indica que, pela homogeneização dos filmes obtidos e a distribuição do ZnOnano na matriz de PHB, há grande probabilidade de inibição, além de dar a garantia de boa formação do filme na metodologia utilizada para a produção destes.

\subsection{Análise termogravimétrica}

De acordo com a análise termogravimétrica (Figura 7A), observou-se que o PHB puro apresentou degradação térmica acima de $297^{\circ} \mathrm{C}$, sendo o material totalmente decomposto em uma única etapa até temperatura próxima de $330{ }^{\circ} \mathrm{C}$. Há dois mecanismos principais de degradação do PHB, o mecanismo de eliminação cis e o de esterificação trans. Mas reações radicalares não 

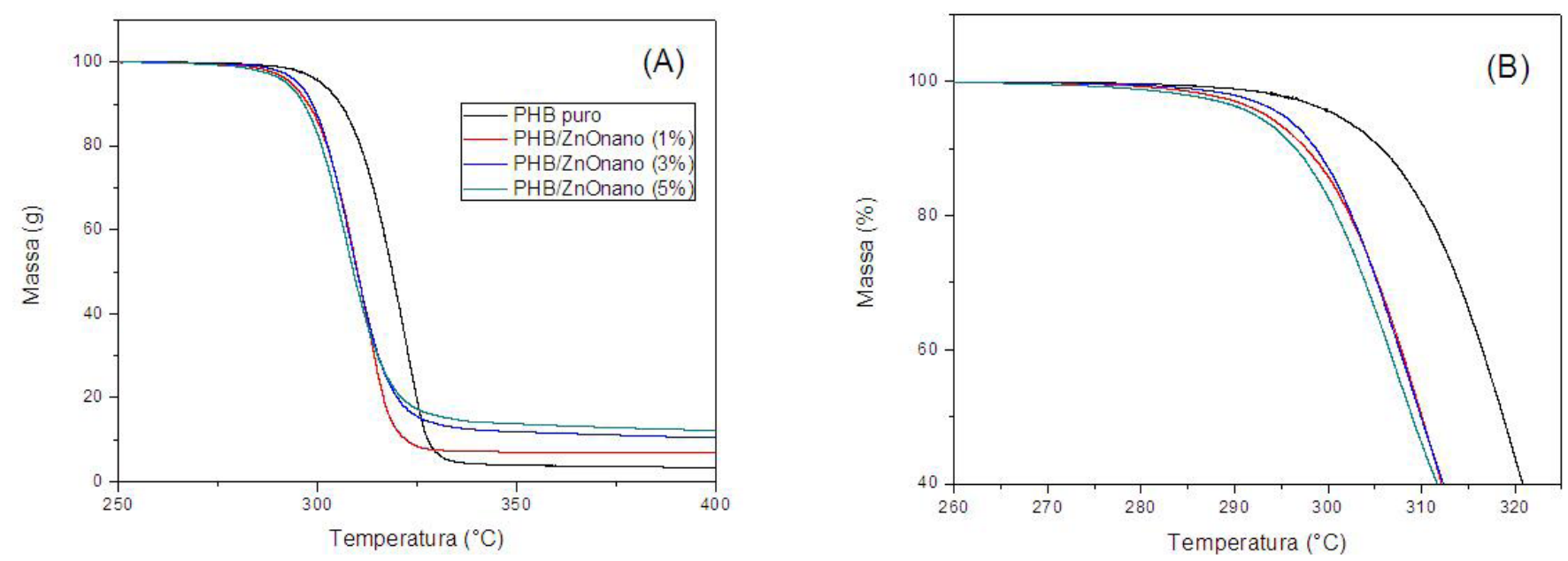

Figura 7. Análise termogravimétrica do PHB puro e PHB/ZnOnano (1\%, 3\% e 5\%), evento completo (A) e destaque da temperatura inicial de degradacão (B).
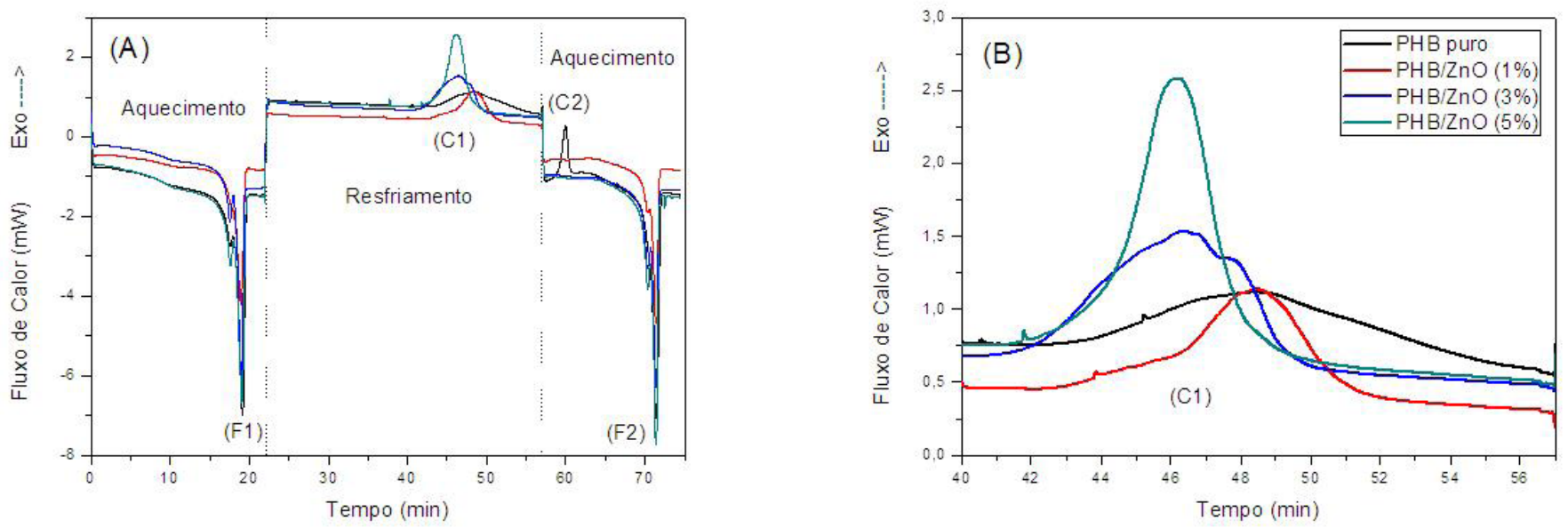

Figura 8. Fluxo de energia em função do tempo para PHB puro e PHB/ZnOnano (1\%, 3\% e 5\%), com tempo de análise entre 0 e 80 min (A) e entre 40 e 57 min (B) (cristalização do fundido).

seletivas podem também estar ocorrendo em temperatura acima de $300^{\circ} \mathrm{C}$ (Aoyagi et al., 2002). Percebe-se também a geração de $3 \%$ de resíduo, que pode ser atribuído à presença das impurezas do processo fermentativo na produção do polímero. Os filmes de PHB/ZnOnano também apresentaram um único estágio de degradação, no entanto, houve a permanência de um resíduo de $8,0 \%$ da massa inicial para o filme com $1 \%$ de $\mathrm{ZnOnano,}$ uma massa residual de $13,0 \%$ para o filme com $3 \%$ de ZnOnano e um resíduo de 15,0\% para o filme com 5\% de $\mathrm{ZnOnano}$. Esses resultados sugerem que a massa residual aumentou em função da nanocarga adicionada. O óxido de zinco $(\mathrm{ZnO})$ só sofre decomposição térmica em uma temperatura próxima à do seu ponto de fusão, que é de $1977^{\circ} \mathrm{C}$. Portanto, para a faixa de temperatura estudada neste trabalho, o óxido não sofre nenhuma transformação química (TAKAHASHI et al., 2007; LIZUNDIA et al., 2016).
Na Figura 7B, o PHB puro apresentou temperatura inicial de degradação de $306{ }^{\circ} \mathrm{C}$ equivalente a $10 \%$ de perda de massa, enquanto que todos os filmes PHB/ZnOnano produzidos começaram as suas respectivas degradações em torno de $296{ }^{\circ} \mathrm{C}$. Essa pequena diminuição na temperatura inicial de degradação é uma característica importante para o processamento dos nanocompósitos e mostra que a adição do nanocompósito reduziu apenas $3 \%$ da temperatura inicial de degradação. Comparando estudos realizados com argilas (D'AMICO et al., 2012), foram obervadas duas funções na estabilidade térmica de nanocompósitos: um efeito de barreira, o que deve melhorar a estabilidade térmica, ou um efeito catalítico sobre a degradação da matriz de polímero, o que deve reduzir a sua resistência térmica. Nesse caso específico, o metal parece induzir reações de hidrólise, que são comuns em poliésteres. Assim, percebe-se que a adição de 
ZnOnano não alterou, de forma significativa, a estabilidade térmica do PHB, para a perda de $10 \%$ da massa inicial do nanocompósito.

A Figura 8A mostra o fluxo de calor no DSC em função do tempo, no intervalo do teste 0-80 minutos para o PHB puro e PHB/ZnOnano (1\%, 3\% e 5\%). Para os filmes de PHB puro e seus nanocompósitos, pode-se observar os quatro eventos de mudança de fase: fusão (F1) da fração cristalina, com pico duplo, durante o primeiro aquecimento, cristalização a partir do fundido (C1) durante o resfriamento, e cristalização a frio (C2) e segunda fusão (F2) durante o reaquecimento. Com a adição do ZnOnano na matriz do polímero, percebe-se uma modificação na cristalinidade deste, pois a adição da carga resulta na completa cristalização do polímero durante o resfriamento, fato que pode ser atribuído à atuação da nanoestrutura como agente nucleante (Figura 8B).

A Figura 9 mostra as curvas de cristalinidade relativa, $X_{\mathrm{C}}$, ou seja, a fração de material cristalizada para o PHB puro e PHB/ZnOnano nos percentuais de 1\%, 3\% e 5\% de ZnOnano. Para o PHB puro e PHB/ZnOnano (1\%), o processo de cristalização é iniciado praticamente na mesma temperatura, entretanto, a partir de $75^{\circ} \mathrm{C}$, a cristalinidade relativa do $\mathrm{PHB} / \mathrm{ZnOnano}(1 \%)$ torna-se maior. Nos filmes com percentuais maiores de ZnOnano (3\% e 5\%), percebe-se que o processo de cristalização ocorre em temperaturas mais altas. Para a indústria, isso significa que, durante 0 resfriamento do material polimérico processado, ocorrerá uma cristalização antecipada, entretanto, a faixa em que se encontra o regime de cristalização será menor para os filmes de PHB/ZnOnano ( $1 \%$, 3\% e $5 \%$ ).

Quando se avalia a taxa de cristalização $\left(\mathrm{min}^{-1}\right)$ (Figura 10), a cristalização do PHB puro é mais lenta; já para os filmes PHB/ZnOnano nanocompósitos, essa cristalização é mais rápida, com destaque para o percentual de $5 \%$ de ZnOnano que apresentou a maior taxa. Percebe-se que o início da cristalização $(x=0,1 \%)$ para os filmes de $\mathrm{PHB}$ puro e $\mathrm{PHB} / \mathrm{ZnOnano} \mathrm{(1 \% )} \mathrm{ocorreu} \mathrm{na} \mathrm{temperatura}$ de aproximadamente $97^{\circ} \mathrm{C}$, já para os $\mathrm{PHB} / \mathrm{ZnOnano}$ (3\% e $5 \%$ ), observa-se um aumento de $5{ }^{\circ} \mathrm{C}$ no início da cristalização (Tabela 3). Acredita-se que essa diferença de $5{ }^{\circ} \mathrm{C}$ não comprometa o processamento desses materiais, uma vez que o processo industrial apresenta uma variação maior que a observada nesse resultado. Outra informação referente aos parâmetros termodinâmicos dos filmes mostra que o percentual de $99 \%$ de cristalinidade ocorre em temperatura de $37,8^{\circ} \mathrm{C}$ para o PHB puro, enquanto que para os nanocompósitos observa-se que há um aumento na temperatura para se atingir essa cristalização máxima. É notória a influência da nanocarga na matriz polimérica referente ao percentual de cristalinidade. O filme de PHB puro apresenta uma cristalinidade de $22,95 \%$, no filme de $\mathrm{PHB} / \mathrm{ZnOnano}(1 \%)$ a cristalinidade aumenta para $43 \%$, no filme $\mathrm{PHB} / \mathrm{ZnOnano}(3 \%)$, para $55 \%$, e, para o

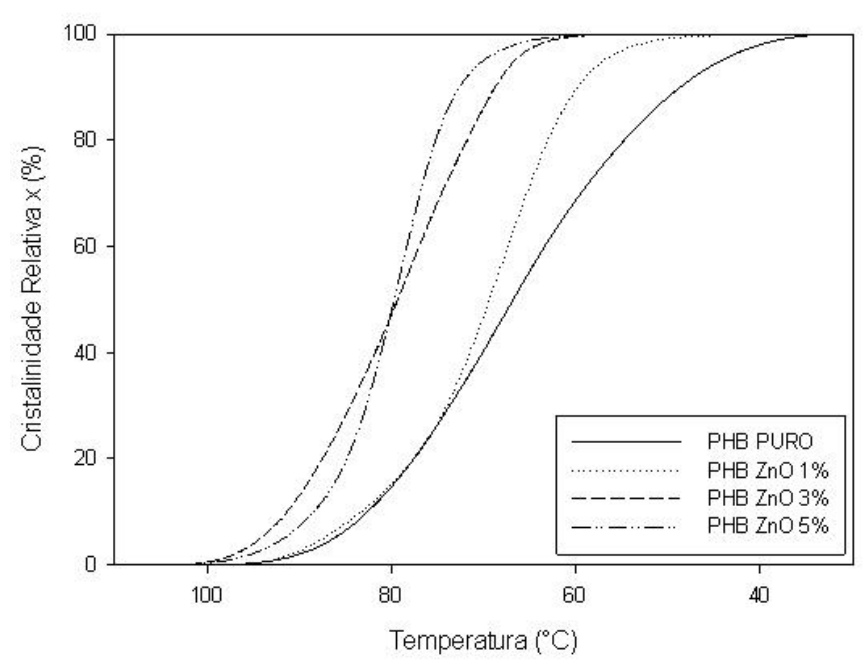

Figura 9. Cristalinidade relativa do PHB puro e dos filmes de PHB/ZnOnano (1\%, 3\% e 5\%).

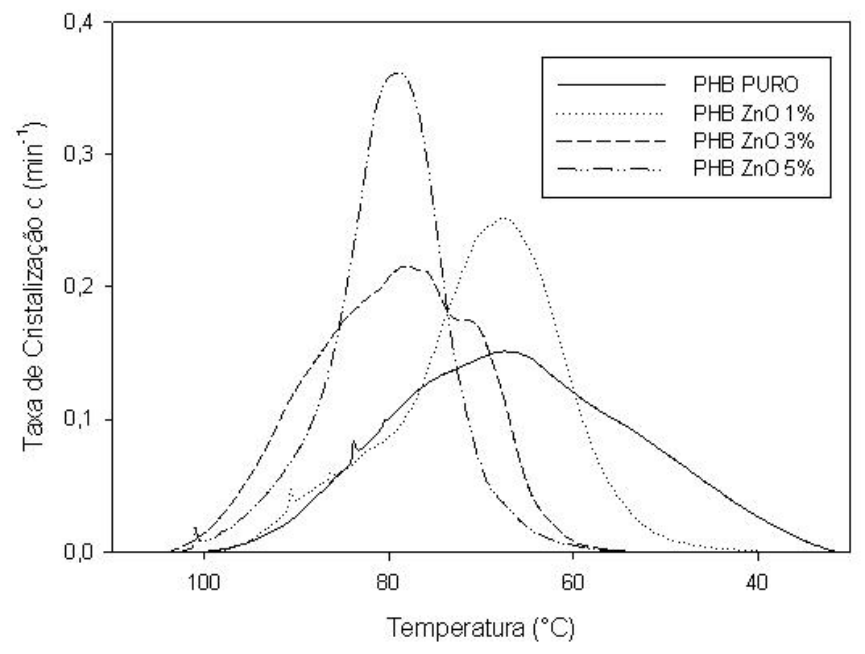

Figura 10. Taxa de cristalização em função da temperatura para PHB puro e PHB/ZnOnano (1\%, 3\% e 5\%).

Tabela 3. Parâmetros termodinâmicos do DSC para amostras de PHB puro e PHB/ZnOnano (1\%, 3\% e 5\%).

\begin{tabular}{cccccc}
$\mathbf{Z n O}$ & $\mathbf{T}(\mathbf{x = 0 , 1} \%)$ & $\mathbf{T}(\mathbf{x}=\mathbf{9 9} \%)$ & $\mathbf{T}_{\mathbf{c}}$ & $\Delta \mathbf{H c}$ & $\mathbf{X c}$ \\
$\mathbf{( \% )}$ & $\left.\mathbf{(}{ }^{\circ} \mathbf{C}\right)$ & $\left({ }^{\circ} \mathbf{C}\right)$ & $\left.\mathbf{(}{ }^{\circ} \mathbf{C}\right)$ & $\mathbf{( J / g )}$ & $(\%)$ \\
\hline 0 & 97,1 & 37,8 & 67,5 & 33,5 & 23,0 \\
1 & 96,5 & 50,8 & 67,7 & 47,8 & 32,8 \\
3 & 102,0 & 62,3 & 78,3 & 51,9 & 35,5 \\
5 & 101,1 & 64,3 & 78,9 & 59,8 & 41,0 \\
\hline
\end{tabular}

filme PHB/ZnOnano (5\%), esse percentual é de $79 \%$. Desta forma, percebe-se que o aumento do percentual de nanocarga aumenta a cristalinidade do polímeros e, quanto mais cristalino o polímero, maior será sua densidade, sua resistência mecânica, sua resistência à dissolução e ao amolecimento pelo calor. Essa alteração 
no comportamento térmico do polímero com a adição de ZnOnano pode ampliar a aplicação industrial do PHB na área de embalagem.

\section{Conclusões}

Filmes de PHB puro e PHB/ZnOnano, nas composições de $1 \%$, $3 \%$ e $5 \%$ em massa de ZnOnano, foram produzidos sob diferentes parâmetros. A morfologia apresentada indica influência dos parâmetros de processamento no resultado final do filme.

A atividade antimicrobiana foi confirmada para o filme de PHB/ZnOnano (5\%) pela presença do halo de inibição do crescimento da bactéria E.coli ao redor do filme. Já os filmes de PHB/ZnOnano (1\% e 3\%) não apresentaram atividade microbiana provavelmente pelo baixo percentual de $\mathrm{ZnO}$. As imagens obtidas por MEV indicam, para todos os filmes, uma superfície homogênea, sem poros, e que o ZnOnano foi incorporado à matriz com boa dispersão, o que favoreceu a atividade antimicrobiana.

As análises por componentes principais, realizadas a partir dos espectros de infravermelho das amostras dos filmes de PHB puro e PHB/ZnOnano (1\%, 3\% e 5\%), indicaram a formação de dois agrupamentos distintos, em função da estrutura química dos polímeros. Este fato pode estar associado a alterações na vibração dos grupos funcionais em função das interações secundárias entre $\mathrm{ZnO}$ e a estrutura do polímero.

No que diz respeito ao comportamento térmico do polímero com a adição da nanocarga, verificou-se que a nanoestrutura não alterou significativamente a estabilidade térmica do polímero. A nanoestrutura funcionou como agente nucleante, pois sua adição resultou numa completa cristalização do PHB durante o resfriamento. Além disso, o aumento do percentual do ZnOnano aumenta a cristalinidade do polímero o que pode ampliar suas aplicações industriais na área de embalagem.

\section{Agradecimentos}

Os autores agradecem à $\mathrm{PHB}$ Industrial S.A. (Brasil) o fornecimento do PHB e ao CNPq e à Fundação de Amparo à Ciência e Tecnologia do Estado de Pernambuco - FACEPE pelo suporte financeiro.

\section{Referências}

ABDELWAHAB, M. A.; FLYNN, A.; CHIOU, B.-S.; IMAM, S.; ORTS, W.; CHIELLINI, E. Thermal, mechanical and morphological characterization of plasticized PLA-PHB blends. Polymer Degradation \& Stability, Pisa, v. 97, n. 9, p. 1822-1828, 2012. http://dx.doi.org/10.1016/j. polymdegradstab.2012.05.036.

AOYAGI, Y.; YAMASHITA, K.; DOI, Y. Thermal degradation of poly[(R)-3-hydroxybutyrate], poly[ $\varepsilon$-caprolactone], and poly [(S)-lactide]. Polymer Degradation and Stability, Yokohama, v. 76, n. 1, p. 53-59, 2002. http://dx.doi.org/10.1016/S01413910(01)00265-8.

ARIFFIN, H.; HARUO NISHIDA, H.; SHIRAI, Y.; HASSAN, M. A. Determination of multiple thermal degradation mechanisms of poly(3-hydroxybutyrate). Polymer Degradation and Stability, Fukuoka, v. 93, n. 8, p. 1433-1439, 2008.

D'AMICO, D. A.; MANFREDI, L. B.; CYRAS, V. P. Relationship between thermal properties, morphology, and crystallinity of nanocomposites based on polyhydroxybutyrate. Journal of Applied Polymer Science, Mar del Plata, v. 123, n. 1, p. 200-208, 2012. http://dx.doi.org/10.1002/app.34457.

BOtAnA, A.; MOLLO, M.; EISENBERG, P.; SANCHEZ, R. M. T. Effect of modified montmorillonite on biodegradable PHB nanocomposites. Applied Clay Science, San Matpin, v. 47, n. 3-4, p. 263-270, 2010. http://dx.doi.org/10.1016/j.clay.2009.11.001.

BRUZAUD, S.; BOURMAUD, A. Thermal degradation and (nano) mechanical behavior of layered silicate reinforced poly(3hydroxybutyrate-co-3-hydroxyvalerate) nanocomposites. Polymer Testing, Lorient Cedex, v. 26, n. 5, p. 652-659, 2007.

DÍEZ-PASCUAL, A. M.; DÍEZ-VICENTE, A. L. Poly(3-hydroxybutyrate)/ $\mathrm{ZnO}$ bionanocomposites with improved mechanical, barrier and antibacterial properties. International Journal of Molecular Sciences, Madrid, v. 15, n. 6, p. 10950-10973, 2014. http:// dx.doi.org/10.3390/ijms150610950. PMid:24941255.

ESPITIA, P.; SOARES, N. F. F.; COIMBRA, J. S. R.; ANDRADE, N. J.; CRUZ, R. S.; MEDEIROS, E. A. A zinc oxide nanoparticles: synthesis, antimicrobial activity and food packaging applications. Food and Bioprocess Technology, Viçosa, v. 5, n. 5, p. 14471464, 2012.

GÓMEZ-ESTACA, J.; LÓPEZ-DE-DICASTILLO, C.; PILAR HERNÁNDEZ-MUÑOZ, P.; CATALÁ, R.; GAVARA, R. Advances in antioxidant active food packaging. Trends in Food Science \& Technology, Valencia, v. 35, n. 1, p. 42-51, 2014. http://dx.doi. org/10.1016/j.tifs.2013.10.008.

HAJIPOUR, M. J.; FROMM, K. M.; ASHKARRAN, A. A.; DE ABERASTURI, O. J.; DE LARRAMENDI, I. R.; ROJO, T.; SERPOOSHAN, V.; PARAK, W. J.; MAHMOUDI, O. Antibacterial properties of nanoparticles. Trends in Biotechnology, Tehran, v. 30, n. 10, p. 499-511, 2012.

HUANG, Z.; ZHENG, X.; YAN, D.; YIN, G.; LIAO, X.; KANG, Y.; YAO, Y.; HUANG, D.; HAO, B. Toxicological effect of ZnO nanoparticles based on bacteria. Langmuir, Chengdu, v. 24, n. 8, p. 4140-4144, 2008.

JIN, T.; SUN, D.; SU, J.; ZHANG, H.; SUE, H. J. Antimicrobial efficacy of zinc oxide quantum dots against Listeria monocytogenes, Salmonella Enteritidis, and Escherichia coli O157:H7. Journal of Food Science, Windmoor, v. 74, n. 1, p. M46-M52, 2009.

LIPOVSKY, A.; NITZAN, Y.; GEDANKEN, A.; LUBART, R. Antifungal activity of $\mathrm{ZnO}$ nanoparticles: the role of ROS mediated cell injury. 
Desenvolvimento e caracterização de filmes à base de Poli(3-hidroxibutirato) aditivado com ZnOnano

Lima Júnior, R. G. et al.

Nanotechnology, Ramat-Gan, v. 22, n. 10, p. 105101, 2011. http:// dx.doi.org/10.1088/0957-4484/22/10/105101. PMid:21289395.

LIZUNDIA, E.; URRUCHI, A.; VILAS, J. L.; LEÓN, L. M. Increased functional properties and thermal stability of flexible cellulose nanocrystal/ZnO films. Carbohydrate Polymers, Derio, v. 136, p. $250-258,2016$.

LÓPEZ DE DICASTILLO, C.; NERÍN, C.; ALFARO, P.; CATALÁ, R.; GAVARA, R.; HERNÁNDEZ-MUÑOZ, P. Development of new antioxidant active packaging films based on ethylene vinyl alcohol copolymer $(\mathrm{EVOH})$ and green tea extract. Journal of Agricultural and Food Chemistry, Zaragosa, v. 59, n. 14, p. 7832-7840, 2011.

PADMAVATHY, N.; VIJAYARAGHAVAN, R. Enhanced bioactivity of $\mathrm{ZnO}$ nanoparticles: an antimicrobial study. Science and Technology of Advanced Materials, Tamil Nadu, v. 9, n. 3, p. 035004, 2008. http://dx. doi.org/10.1088/1468-6996/9/3/035004.

RAGHUPATHI, K. R.; KOODALI, R. T.; MANNA, A. C. Size-dependent bacterial growth inhibition and mechanism of antibacterial activity of Zinc Oxide nanoparticles. Langmuir, Vermillion, v. 27, n. 7, p. 4020-4028, 2011. PMid:21401066.
ROA, J. P. B.; PATRÍCIO, P. S. O.; ORÉFICE, R. L.; LAGO, R. M. Improvement of the thermal properties of poly(3-hydroxybutyrate) (PHB) by low molecular weight polypropylene glycol (LMWPPG) addition. Journal of Applied Polymer Science, Belo Horizonte, v. 128, n. 5, p. 1097-4628, 2013.

SANTOS, A. M. P.; SANTOS, E. J. P. Pre-heating temperature dependence of the c-axis orientation of $\mathrm{ZnO}$ thin films. Thin Solid Films, Recife, v. 516, n. 18, p. 6210-6214, 2008.

SILVA, M. R. B.; TAVARES, M. I. B.; SILVA, E. O.; CUCINELLI NETO, R. P. Dynamic and structural evaluation of poly(3hydroxybutyrate) layered nanocomposites. Polymer Testing, Rio de Janeiro, v. 32, n. 1, p. 165-174, 2013. http://dx.doi. org/10.1016/j.polymertesting.2012.09.006.

TAKAHASHI, K.; YOSHIKAWA, A.; SANDHU, A. (Ed.). Wide bandgap semiconductors: fundamental properties and modern photonic and electronic devices. Berlim: Springer Science \& Business Media, 2007.

WELLEN, R. M. R.; RABELLO, M. S.; FECHINE, G. J. M.; CANEDO, E. L. The melting behaviour of poly(3-hydroxybutyrate) by DSC: reproducibility study. Polymer Testing, Campina Grande, v. 32, n. 2, p. 215-220, 2013. 